\title{
FROM "INTERACTIVE GENERATIVE FORMATIONS" TO "INTERACTION WITH TECHNOLOGICAL ORGANISM"
}

\author{
Svetoslav Kosev, Atanas Markov \\ kosevsa@gmail.com \\ Department of Graphic Design and Visual Communication, \\ University of Veliko Turnovo "St. St. Cyril and Methodius", Bulgaria
}

\begin{abstract}
The installation "Interacting with a technological organism" is a natural consequence of two previous interactive projects, namely "Interactive Generative Formations" and "Virtual Arena". The most significant difference is that for the first two projects, the events occur on a two-dimensional plane on which images are projected. The aesthetics of the objects are specified in advance, and the movement of the spectators, which are participators as well, is captured by a sensor. In this way, observers change the look of dynamic images, becoming an active part of their aesthetics. With the project "Interaction with a technological organism", we leave the area of two-dimensional and move into three-dimensional space.

The space in which the events take place is sized: $500 \times 500 \times 350$ $\mathrm{cm}$. During discussions, the authors came up with the idea to imitate a living organism that reacts to approaching.

Keywords: Interactive Art; Interactive Installation
\end{abstract}

\section{ОТ „ИНТЕРАКТИВНО ГЕНЕРАТИВНИ ФОРМАЦИИ“АО „ВЗАИМОАЕЙСТВИЕ С ТЕХНОАОГИЧЕН ОРГАНИЗЪМ“}

\author{
Светослав Косев, Атанас Марков \\ Великотърновски университет „Св. Св.Кири^ и Методий“, \\ кателра "Графичен Аизайн и визуални комуникации"
}

Резюме: Инсталацията „Взаимодействие с технологичен организъм" е естествено следствие на Авата предхолни интерактивни проекта, а именно „Интерактивно генеративни формации“ и „Виртуална арена“. Най-съществената разлика е, че при първите $А в а$ проекта, събитията се случват на Авуизмерна п^оскост, върху която се прожектират изображения. Естетиката на обектите е предварително уточнена, а движението на наблюдаващите и същевременно участващи в произвеАението зрители, се прихваща от сензор. По този начин наблюдателите променят визията на Аинамичните изображения, като стават активна част от тяхната естетика. С проекта „Взаимодействие с технологичен организьм", напускаме зоната на двуизмерното и преминаваме в триизмерното пространство. Пространството в което се развиват събитията е с размери 500×500×350 см. В 
процеса на разговори стигнахме ло илеята, да имитираме жив организъм, който реагира на приближаване към него.

КАючови Ауми: интерактивно изкуство; интерактивна инсталация

Интерактивните проекти винаги будят интереса на наб^юАаващите и основната причина за това е прякото взаимодействие межАу обекта и въвлечения в ситуацията субект. Интеракцията се използва като метол на обмяна на инорормация в много широк периметьр от области с различна насоченост и характер (Shanken, 2002), (Glassner, 2010), (Stern, 2011), (Shiffman, 2008), (Trifonova et al., 2008). Особено Аобри резултати дава например, като средство за обучение във всички възрастови групи. Аруго успешно поле на нейното приложение е психологията и тъй като тези Аве области на науката вървят ръка за ръка, често се среща в тяхната комбинация. В конкретния случай на настоящото представяне, интеракцията е използвана с це^ създаване на произведения на изкуството, които са създалени в различен времеви Аиапазон от авторите на този Аоклал, а именно Светослав Косев и Атанас Марков.

По отношение на причината за тяхната поява може $а$ а се каже, че първият от проектите, носещ името „ИНТЕРАКТИВНО ГЕНЕРАТИВНИ ФОРМАЦИИ" (Фиг.1), беше съзАален с експериментална цел.

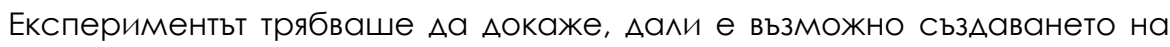
произведение с естетическа стойност, чрез високотехнологични средства. Тук трябва да се каже, че от чисто технологична глеАна точка, тази комбинация от програмиране и сензор за прихващане на Авижението, не е някаква новост. За $а$ а създалем тази инсталация, използвахме сензор Kinect за Хbox, а програмата, която визуализира Авижението на преминаващите прел вьпросния сензор е Open source coopтуера Processing. Въпросът беше, чрез тези срелства $\Delta$ a се постигне еорект на художествено произведение. Годината в която съзАалохме ИНТЕРАКТИВНО ГЕНЕРАТИВНИ ФОРМАЦИИ" е 2014 Г. ПървоначаАНО преАставихме инсталацията в София във врьзка с изложба "Преподаватели и студенти" - Виваком арт хол (Фиг. 1). Последваха представяния в университета в Ниш, Сърбия през същата голина, слеА което го демонстрирахме и в Escuela de Arte de Murcia, Мурсия, Испания през 2016. Може $а$ а се каже, че на всяко енно от изброените 
места, инсталацията предизвикваше желаната реакция и полобаващ интерес.

Като еАно от значимите места, където беше позициониран този проект и кьм Анешна Аата 18 апри^ 2019 г. все още пребивава, е Музея на хумора и сатирата - Габрово. Той беше представен на вниманието на посетителите в музея, по случай студентския празник 8 Аекември през 2017 г. и от тогава не е спира^ $\Delta а$ фонкционира.

По думите на директора на Музей на хумора и сатирата г-жа маргарита Аоровска „Това е най-прольлжително изложената интерактивна инсталация в България".

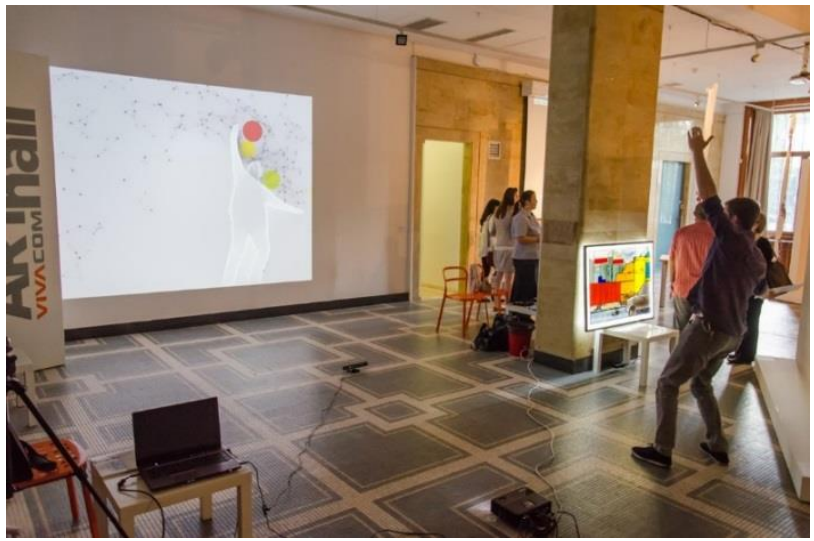

\section{Фиг. 1. Проект „Интерактивно генеративни формации“}

Виваком арт хол, София

На практика проекта „Интерактивно генеративни формации“ представлява еАин Аиалог межАу зрителя и произведението. Това е еАно виртуално поле в което всеки зрител се появява на екрана като силует във виА на мрежа от Аинии и има способността $А$ в вияе на самото произведение. Аиниите са свързани с алгоритьм, което прави произведението освен интерактивно и генеративно, което е инспирирало и заглавието на проекта. В тази виртуална срела свобо но на псевАослучаен принцип се разпрьсква мрежа от точки, които имат опреАели фоизични свойства.

Те също се свързват помежау си със същия алгоритьм като контура на зрителя, като по този начин се тьрси графииното усещане. 
Малките точки имат гравитация и палат, но също така могат Аа взаимодействат при сбльсък с потребителите или помежАу си. В Аопьлнение има и по-големи цветни „топки“, които също участват в тази виртуална сцена с физични зависимости. Целта на послеАните е $А$ व полтикне зрителя към по-активно участие и чрез елемент на игра $а$ а бъде въвлечен в тази виртуална среда.

По отношение на втората инсталация, носеща наименованието „Виртуална арена" (Фиг. 2) може $\Delta а$ се каже, че не беше особено успешна, тъй като интерактивността в нея се изразяваше в появата на зрителя във виртуалната срела. Аипсата на взаимодействие с обекти от обкръжаващата среда, кара зрителите $а$ а губят интерес.

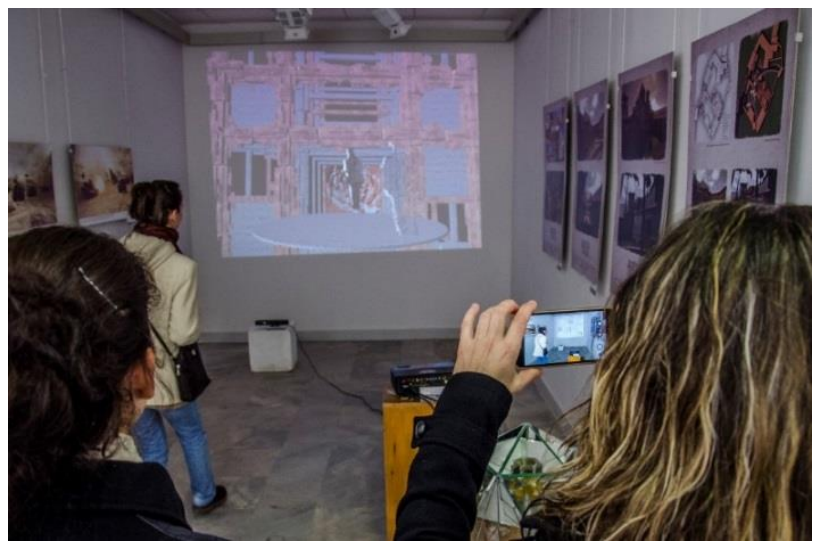

Фиг. 2. Проект „Виртуална арена“

Изложбени зали „Рафраел Михайлов“, Велико Търново

Инсталацията „Взаимодействие с технологичен организъм“ е естествено следствие на Авата предходни интерактивни проекта, „Интерактивно генеративни формации“ и „Виртуална арена“. Тъй като вече бяхме реализирали споменатите Ава интерактивни проекта решихме, че вместо $\Delta а$ се представяме като отлелни имена, можем $\Delta а$ сьздалем арт група, която $\Delta а$ е ориентирана към интеракцията в изкуството.

По този начин се появи и група Co-interaction, която стана ^ицето на Аосега реализираните от авторите проекти, с тенденцията $\Delta$ а се появят и слеАващи такива. Най-съществената разлика на третата инсталация от останалите е, че при пьрвите Ава проекта, събитията се 
случват на Авуизмерна плоскост, върху която се прожектират изображения. Естетиката на обектите е предварително уточнена, а Авижението на наблюдаващите и същевременно участващи в произведението зрители, се прихваща от сензор.

По този начин наблюдателите променят визията на Аинамичните изображения, като стават активна част от тяхната естетика. С проекта „Взаимодействие с технологичен организьм" (Фиг. 3), напускаме зоната на Авуизмерното и преминаваме в триизмерното пространство. Пространството в което се развиват събитията е с размери 500×500×350 см. В процеса на разговори стигнахме Ао илеята, Аа имитираме жив организъм, който реагира на приближаване към него.

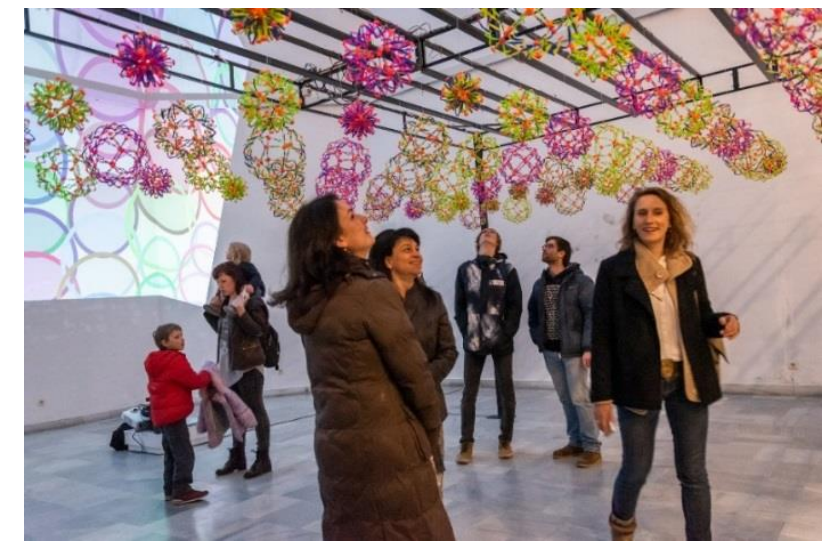

\section{Фиг. 3. Проект „Взаимодействие с технологичен организъм“}

Изложбени зали „Рафрае^ Михайлов“, Велико Търново

Базовият моде^ беше група от оримма „Аватар“, в който главният герой при Аокосването на еАно растение (Helicoradian), преАизвика мигновена реакция от страна на цяла група такива от същия виА, при което всички те се скриват в основата си (Фиг. 4).

3а sa се развие инсталация от желания мащаб в зоната на стьпване на наблюдателите обаче е рисковано. Порали тази причина решихме Аа влигнем обектите нал главите на хората, което разбира се е по-сложно от инженерна глеАна точка и изисква намесата на специалист в съответната област. 


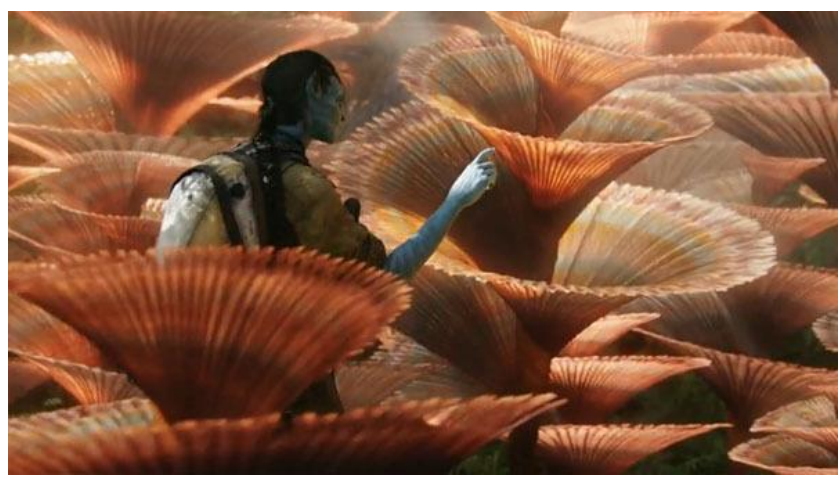

Фиг. 4. Растение Helicoradian от фимма „Аватар“

Аругият проблем беше „Какьв Аа е обектьт, който ще реагира на присьствието на зрителя и как точно ще се случи това?" Тогава се сетих за детска играчка, която бях вижАал на п^ажа. Тя преАставляваше свита топка, която се отваря при хвърляне и се затваря, когато я хванеш. В последствие се оказа, че тази детска играчка е известна в научните среди като "Сорера на Хоберман". Направихме няколко експеримента с нея и се оказа, че може да бъле отваряна и затваряна сьс залален размер с помощта на серво машинки. В послелствие на базата на тези пьрвоначално предвилени елементи, беше изгралена цялата конструкция за инсталацията. Като фринален щрих бе Аобавен и музикален фрон, композиран от Георги Млячков. Естествено имаше и редица проблемни моменти в които се налагаше Атанас $а$ а решава проблеми свьрзани предимно с електрониката. В крайна сметка резултатьт от съвместната Аейност в пьрвоначалния етап кьАето концептуалната и визуална част беше решена от мен, техническата част, поета изцяло от Атанас, както и безценното съдействие на инж. Антон Крьстев по отношение на носещата конструкция е налице.

При процеса на реализиране и анализ и на гореописаните авторски проекти и при направеното проучване на артисти, занимаващи се в тази област, се стигна АО някои важни извоАи.

Най-важният от тях, е че това е интерАисциплинарна залача и трябва да се планира и изпьлни от екип от различни специалисти, за Аа се постигнат значими успехи. Вторият, че трябва $\Delta$ а се спази някаква метолика при проектирането и изграждането. От натрупания опит 
стигнахме Ао слеАните основни четири стьпки при реализацията на интерактивен арт проект със среАствата на компютърни технологии:

1. При реализиране на интерактивни арт проекти трябва $А а$ се направи много полробен п^ан, в който $А$ व се преАвиАят всички фрактори които ще повлияят при окончателната реализация. Пьрвата стьпка от п^ана е $\Delta$ a се поставят естетическите търсения и тьрсената реакция на публиката. Тук най-важният член от екипа е художника (творец, артист) или творчески екип, който задава основната концепция на проекта и каква точно ще е интеракцията със зрителите. Аобре е $а$ полготви визуален материал, който в послелствие $а$ б бъле прелставен на останалите членове от екипа, както и на евентуални спонсори и организатори на събития. Следваща стьпка е обмислянето на технологичните решения. Тук в зависимост от мащаба на проекта могат $\Delta$ а се включат софртуерен разработчик, хардуерен инженер, звуков или вилео оператор и $и$ р. в зависимост от конкретната реализация. Тяхната залача на този етап е $\Delta а$ преценят кои от илеите на артиста с какви технически средства $А$ б бъат реализирани, $А$ колко въобще могат $\Delta$ व се реализират с наличната технология и $а$ а оценят ффинансово реализацията на проекта. СлеАва (ако се налага) корекция в пьрвоначалното залание, като проектирането се съобразява с предложените технически реализации, бюджета и Аопустимата естетика на интеракция.

2. Втора стьпка слеА планирането е прототипиране. СъзАават се еАин или няколко по-малки проекта и/или прототипа на технологии, които ще бъАат вложени в окончателния проект. Така стават по-ясни и крайните цели на екипа от разработчици. Например какви сензори за обратна врьзка ще бълат използвани, врьзката им с конкретна софртуерна среда, какво изхолно устройство или механизъм ще се използва, колко електрически ток или Аруги ресурси ще консумира и т.н.

3. Следващият етап е реализацията на окончателния вариант. Тук се залага ^огиката на Аействия и реакция, залалена от творческия екип. Това се реализира най-често от софртуерни разработчици, които програмират Аанните от различни сензори и управлението на различни устройства. Изграждат се необходимите конструкции, електронни управления, електрически елементи и Ар. и се свързват в еАно. Важно е авторьт на илеята да слеАи конкретните хардуерни реализации, за да не се избяга от пьрвоначалната илея. 
4. Посленната стьпка е свързана с тестване и настройка. Тук се изчистват грешки в програмния коА, харАуерни проблеми, възникнали в процеса на изграждане, логистични проблеми и Ар. Отново е важно творческият екип $\Delta а$ тества, за $\Delta$ а установи $\Delta а \wedge и$ е постигнат интерактивния опит, който е търсен и $А$ ии визуално са спазени заланията. Настройката е свьрзана със средата, в която ще бъле експонирано произведението, както и с различни програмни параметри.

В заключение може $\Delta$ a ce каже, че чрез високотехнологични средства, могат $а$ а се получат впечатляващи от естетическа гленна точка резултати. Особено важно обаче е в случая е доверието межлу членовете на екипа. Което означава, че егото присъщо на повечето творци в областта на визуалните изкуства, трябва да намери своя баланс и резултатьт $\Delta а$ бъле сполелен.

\section{АИTEPATYPA / REFERENCES}

Glassner, A. (2010). Processing for Visual Artists: How to Create Expressive Images and Interactive Art. A. K. Peters, Ltd, MA, USA (C2010

Shanken, Edward A. (2002). Art in the Information Age: Technology and Conceptual Art, Leonardo, Vol. 35, No. 4. (2002), pp. 433-438.

Shiffman, D. (2008). Learning Processing: A Beginner's Guide to Programming Images, Animation, and Interaction. Morgan Kaufmann Publishers Inc. San Francisco, CA, USA @2008

Stern, Nathaniel, (2011). The Implicit Body as Performance: Analyzing Interactive Art, Leonardo, Vol. 44, No. 3 (2011) (pp. 232-238)

Trifonova, Anna; Jaccheri, Letizia; Bergaust, Kristin, (2008). Software engineering issues in interactive installation art. International Journal of Arts and Technology, 2008, 1.1: 43-65.

\section{Интернет източници / Internet Sources:}

Generative Design, [http://www.generative-gestaltung.de] , (Last view: 01.09.2019)] 


\section{КУАТУРНО-ИСТОРИЧЕСКО НАСАЕАСТВО: \\ ОПАЗВАНЕ, ПРЕАСТАВЯНЕ, АИГИТААИЗАЦИЯ}

CULTURAL AND

HISTORICAL

HERITAGE

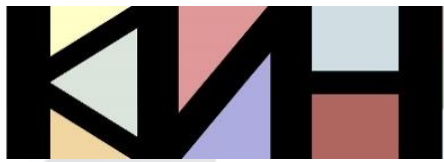

PRESERVATION PRESENTATION

DIGITIZATION
Материалите в сборника са обект на авторско право. Разрешава се безвъзмезАното ползване на техни електронни/ хартиени копия само за лична употреба или обучение, при пь^но цитиране на текущата страница и слеА писмена дек^арация от цитиращия за Аипса на търговски намерения. За копиране пол Аруга фрорма, препубликуване или публикуване на сървъри се изисква писмено разрешение и/или заплащане.

() Авторски колектив, 2019 Технически реАактори: Николай Ноев Калина Сотирова-Вълкова Ка^оян Николов

\section{Editors}

Galina Bogdanova Vanya Mateeva

This work is subject to copyright. Open and free of charge use of digital/hard copies of publications is granted only for personal or educational use, with full citation of the current page, and after written declaration of the quoting side for not-commercial Intention. For any other reproducing types, republishing, photocopying, recording, or any other storage retrieval system/ server written permission and/or fee is required.

(C) Authors` Group, 2019

Technical editors:

Nikolay Noev

Kalina Sotirova-Valkova

Kaloyan Nikolov

Научна поредица: том 5, брой 2 (7)/2019

Science series: vol. 5 , issue $2(7) / 2019$

www.math.bas.bg/vt/kin

ISSN: 2367-8038 